\title{
Investigation of health professionals' knowledge retention in CPR after completing the Advance Life Support in Gynecology (ALSG) Course
}

Nikolaos Vrachnis ( $\square$ nvrachnis@hotmail.com )

National and Kapodistrian University of Athens Faculty of Medicine

Nikolaos Antonakopoulos

National and Kapodistrian University of Athens

Antigoni Tsigirlioti

National and Kapodistrian University of Athens

Vasilios Pergialiotis

National and Kapodistrian University of Athens

Nicoleta lacovidou

National and Kapodistrian University of Athens

Zoi lliodromiti

National and Kapodistrian University of Athens

Research article

Keywords: life support course in gynecology, ALSG course, knowledge retention, CPR, instructors, continuous education

Posted Date: August 12th, 2020

DOl: https://doi.org/10.21203/rs.3.rs-47957/v1

License: (c) (i) This work is licensed under a Creative Commons Attribution 4.0 International License.

Read Full License 


\section{Abstract \\ Background}

Studies have shown that immediate and effective cardiopulmonary resuscitation plays a major role in the survival of victims of cardiac arrest. Numerous studies also demonstrate the need for continuous training of health professionals. In Greece life support courses are established in various fields including pediatrics, obstetrics and gynecology. The ALSG (Advanced Life Support in Gynecology) course was initiated in 2011 and covers gynecological emergencies that often lead to cardiopulmonary arrest, including ruptured ectopic pregnancy, toxic shock syndrome and postoperative collapse. The purpose of this study was to investigate knowledge retention in CPR after completion of the ALSG course and to define the factors affecting it.

\section{Methods}

A descriptive qualitative study was, designed and conducted through anonymous questionnaires sent electronically to past ALSG course participants.

\section{Results}

A total of 100 questionnaires were sent and 50 were completed and returned. Mean knowledge retention was $87.4 \pm 18.2$. The multivariate analysis revealed that the time interval since training in life support significantly correlated with the actual score. Additionally, more correct answers were given by course instructors than certified course graduates.

\section{Conclusion}

Instructors in life support courses achieve longer retention of their knowledge than trainees, while increased time interval between training and knowledge recall results in lower scores. In conclusion, continuing education of health professionals and adoption of algorithms, such as those taught in the ALSG course, are likely to help maintain knowledge and achieve high standards of care.

\section{Background}

Many studies have shown that immediate and effective cardiopulmonary resuscitation (CPR) plays a major role in the survival of victims of cardiac arrest [1-3]. Efficacious CPR includes application of an effective technique along with prompt use of the defibrillator [4]. Moreover, several studies have demonstrated the need for continuous education of health professionals in basic and advanced life support, with the majority of these studies including doctors and nurses in the studied population [5-7]. The Advanced Life Support in Gynecology (ALSG) course started in Greece in 2011 and was incorporated 
in ongoing training and education. The aim of the course is to ensure that all participants who successfully complete it will be able to manage gynecologic emergencies that may result in serious morbidity of mortality of women.

Retention of theoretical skills following the completion of courses remains, however, a critical issue; therefore, re-evaluation of the participants` knowledge seems to be prudent. Previous studies suggested that several factors seem to affect the success of advanced life support training programs, including the pre-course resuscitation knowledge, younger age and professional background [8]. To date, evidence concerning long term retain of skills among trainees that completed the ALSG course is lacking from the international literature as well as the factors that may actually affect knowledge retention. This information is considered important as it may provide significant data that can help structure the reevaluation of participants; hence, optimizing knowledge retention in the long term setting and ensuring the competence of participants in medical emergencies [8].

This study aimed to investigate health professionals' knowledge retention in CPR after completing the ALSG Course in order to confirm the usefulness of participating in such courses by health professionals of different grades and specialization and, potentially, to indicate the need for improvement of the efficiency and power of knowledge transmission and long-term retention.

\section{Materials And Methods}

This is a descriptive and qualitative study that was conducted by sending e-mail questionnaires to past participants in the course. The involved health professionals were gynecologists, gynecology registrars, midwives and nurses. The questionnaire focused on theoretical knowledge alone and was not oriented in evaluating the practical skills of participants (Appendix). Addressed questions were divided in two main parts, those that evaluated the baseline characteristics of particpants including their demographic characteristics (including age, sex, marital status, level of education, and professional status as well s the history and timing of participation in ALSG courses),. The participants` theoretical background was also evaluated using a structured questionnaire that covered the entire spectrum of basic and advanced life support in gynecology to ascertain their understanding in key issues related to CPR. For each question there was only one correct answer. Therefore, the range of responses was from 0 to 10 . The study took place between February 2013 and November 2014.

\section{Statistical analysis}

Continuous variables are presented as mean and standard deviation (SD). Quantitative variables are presented with absolute and relative frequencies. Student's t-test was used to compare means values. For the comparisons of proportions, we used the chi-squared and Fisher's exact tests. All reported p-values are two tailed. Statistical significance was set at $p<.05$ and all analyses were conducted using the SPSS statistical software (version 21.0) (IBM Corp. Armonk, NY, USA). 


\section{Results}

The ALSG course was attended by 100 participants during the time that our study was conducted. In total, 100 questionnaires were sent out and 50 were completed and returned. The baseline demographic characteristics of participants as well as their training in life support are shown in Tables 1 and 2. Seventy-two percent (72\%) of respondents had attended an ALSG course, $72 \%$ of them had participated in another life support course and $22 \%$ were instructors in life support courses. Figure 1 presents the answers given by participants and their scores. The mean knowledge score was $87.4 \%$, the standard deviation was $18.2 \%$ and the median was $95 \%$, with the minimum value being $20 \%$ and the maximum value being $100 \%$. Table 3 shows the correlations between demographic characteristics, life support educational status and scoring.

Table 1

Demographic characteristics of participants

\begin{tabular}{|c|c|}
\hline \multirow[t]{2}{*}{ Demographic characteristics of participants } & $N(\%)$ \\
\hline & a. mean value (standard deviation) \\
\hline \multicolumn{2}{|l|}{ Sex } \\
\hline Male & $33(66,0)$ \\
\hline Female & $17(34,0)$ \\
\hline Age & $36,9(5,8)^{a}$ \\
\hline \multicolumn{2}{|l|}{ Marital status } \\
\hline Single/divorced & $26(52,0)$ \\
\hline Married & $24(48,0)$ \\
\hline \multicolumn{2}{|l|}{ Educational level } \\
\hline Technological institution graduates & $7(14,0)$ \\
\hline University graduates & $43(86,0)$ \\
\hline \multicolumn{2}{|l|}{ Attribute } \\
\hline Interns & $8(16,0)$ \\
\hline Specialised & $35(70,0)$ \\
\hline Midwifes & $5(10,0)$ \\
\hline Nurses & $2(4,0)$ \\
\hline Years of working experience & $8,7(4,4)^{a}$ \\
\hline Years from graduation & $10,9(5,2)^{a}$ \\
\hline
\end{tabular}


Table 2

Participants' characteristics regarding life support training

\begin{tabular}{|l|l|}
\hline Participants' characteristics regarding life support training & $\begin{array}{l}\text { N (\%) } \\
\text { a. mean value (standard } \\
\text { deviation) }\end{array}$ \\
\hline Previous training in advanced life support in gynecology & $12(24,0)$ \\
\hline No & $38(76,0)$ \\
\hline Yes & $2,7(1,1)^{\mathrm{a}}$ \\
\hline $\begin{array}{l}\text { Years since previous training in advanced life support in } \\
\text { gynecology }\end{array}$ & $14(28,0)$ \\
\hline Previous training in life support & $36(72,0)$ \\
\hline No & $4,0(2,8)^{\mathrm{a}}$ \\
\hline Yes & $39(78,0)$ \\
\hline Instructor in life support seminar & $11(22,0)$ \\
\hline No & $2,0(1,3)^{\mathrm{a}}$ \\
\hline Yes & \\
\hline Years since last seminar in life support as instructor & \\
\hline
\end{tabular}


Table 3

Correlations of life support educational status and scoring

\begin{tabular}{|c|c|c|}
\hline Feature & $\begin{array}{l}\text { Mean value of knowledge (standard } \\
\text { deviation ) }\end{array}$ & $\begin{array}{l}\text { p-value } \\
\text { a. T-test } \\
\beta \text {. } \\
\text { Pearson }\end{array}$ \\
\hline Educational level & & $0,9^{a}$ \\
\hline Technological Institution graduates & $87,1(13,8)$ & \\
\hline University graduates & $87,4(18,9)$ & \\
\hline Attribute & & $0,9^{a}$ \\
\hline Doctors & $87,4(18,9)$ & \\
\hline Midwives/nurses & $87,1(13,8)$ & \\
\hline Years of experience & $0,03^{\beta}$ & $0,8^{\beta}$ \\
\hline Years from graduation & $0,14^{\beta}$ & $0,4^{\beta}$ \\
\hline Previous training in ALSG & & $0,3^{a}$ \\
\hline No & $82,5(14,8)$ & \\
\hline Yes & $88,9(19,0)$ & \\
\hline Years since last training in ALSG & $-0,47^{\beta}$ & $0,003^{\beta}$ \\
\hline Previous training in life support & & $0,8^{a}$ \\
\hline No & $86,4(10,8)$ & \\
\hline Yes & $87,8(20,4)$ & \\
\hline Years since last training in life support & $-0,24^{\beta}$ & $0,16^{\beta}$ \\
\hline Instructor in life support seminar & & $<0,001^{a}$ \\
\hline No & $84,3(19,4)$ & \\
\hline Yes & $98,2(4,0)$ & \\
\hline $\begin{array}{l}\text { Years since last seminar in life support as an } \\
\text { instructor }\end{array}$ & $0,00^{\beta}$ & $0,99^{\beta}$ \\
\hline
\end{tabular}

The multivariate analysis showed a statistically significant relationship between knowledge score and time interval since training received on advanced life support in gynecologic emergencies $(p=0.003)$ and knowledge score and educational status as instructor $(p<0.001)$. According to our results, instructors of 
life support courses achieved higher scores than non-instructors, while increased time interval between training and knowledge recall results in lower scores.

\section{Discussion}

Our study clearly indicates that reevaluation of participants in ALSG courses is essential to promote retention of skills, as progressive limitation of theoretical knowledge was observed in our series. Moreover, indirect evidence supports the importance of subsequent training, which is per se acquired by all instructors. Instructors of the ALSG course possess in-depth knowledge of the skills which they teach in life support courses which they replenish at regular intervals.

Emergency life support training furnishes professionals with the skills to help someone in a lifethreatening situation until further expert assistance arrives. Worryingly, Greece has one of the lowest proportion of professionals trained in emergency life support in Europe, despite the fact that a significant proportion of the general population may ultimately need cardiopulmonary resuscitation. This raise concerns concerning the diagnostic work-up and management of patients that present with medical emergency. The actual reasons that may underlie this effect remain to be elucidated, as there are no data to draw firm conclusions. It is believed, however, that in most cases physicians do not attend these courses due to lack of awareness concerning their existence and/or inability to access the organizing committees. A common misperception concerning emergency life support procedures is fear of legal allegations in cases that will ultimately develop severe morbidity and mortality. Structured programs aim at reducing this fear as they provide attendants the theoretical and practical background that ensures proper and efficacious handling of these patients [9].

Nevertheless, it is important to encourage participants to regularly refresh their skills by repeating courses every few years. In the longer term, the emergency services should work together to promote and deliver emergency life support training.

Life support courses in Greece are organized by scientific organizations and participation is voluntary. Certification renewal is offered every 3-5 years. In this study, as in others with similar endpoints, it has been proven that knowledge declines after an average time interval of six months [10]. Knowledge retention among adults participating in adult advanced life support (ALS) courses has been already reviewed by Yang et al in a systematic review that included 11 papers [11]. The authors of this paper observed a gradual decay in knowledge and skills which starts 6 months to 1 year following completion of training, with skill decay being faster compared to knowledge decay. Given this information we recommend that certification renewal should be offered at a shorter time interval that will allow proper revalidation of participants. In countries like Greece that face the problem of economic recession skill reassessment should ideally be done with an affordable economic fee and, if possible, with no charge at all.

The actual methodology that would help reduce knowledge and skill decay overtime has been recently reviewed by Au et al in the field of advance resuscitation training [12]. In their systematic review which 
included 16 studies and 1,192 participants the authors reported that simulation-based interventions, refresher courses and adjustments to the courses ' content during re-evaluation and re-training of participants were of detrimental importance in retaining the required level of knowledge.

Taking this information into account we believe that the incorporation of a structured course of advanced gynecological life with re-evaluation of skill and knowledge retention within the first year is essential to increase physician and paramedical stuff awareness concerning current guidelines and algorithms in advanced life support $[13,14]$. In this way, involved healthcare providers will be able to provide higher quality care in the field of gynecology, be able to incorporate such information into clinical practice and respond to emergencies with confidence. Adoption of algorithms to deal with gynecological and other emergencies, standardization of processes and continuous training of health personnel seems to be the correct strategy to improve CPR efficacy in cases of emergencies and to achieve high survival rates [1315].

\section{Strengths and limitations of our study}

Our study presents for the first time in the international literature evidence concerning knowledge retention among participants that have attended an ALSG course and indicates the significance of revalidation of their knowledge. Nevertheless, its main limitation is the inability to include a control group that has already attended a second course of the program; hence, evaluating the potential beneficial effect of the latter in enhancing the understanding of participants. Moreover, data concerning the actual practical skills of involved providers remain, still, unknown; hence, application of theoretical knowledge remains unknown.

\section{Directions for future research}

The importance of advanced life support has been stressed in various medical fields. Knowledge retention remains, however, as previously stated, an important issue. Future research should study the usefulness of revalidation programs and determine the optimal interval between the first and sequential courses. It would be also useful to take in mind the actual involvement of participants in cases in real life and request their evaluation concerning the actual benefit of the course. Lastly, it is expected that the more courses a participant attends the more experience he gains; thus, determination of the least number of courses that is needed to gain long-term experience should be studied.

\section{Conclusions}

Advanced life support in gynecology provides significant theoretical information that can be used in medical emergencies. However, retention of knowledge remains still an issue and the optimal number of repeated courses to gain long-term experience, as well as the factors that seem to enhance knowledge retention remains still to be determined.

\section{List Of Abbreviations}


cardiopulmonary resuscitation (CPR)

Advanced Life Support in Gynecology (ALSG)

\section{Declarations}

\section{Ethic approval and consent to participate}

All participants provided written informed consent and were assigned identification numbers to ensure confidentiality. Research and ethics committe approval number of the Hellenic Society of Obstetric and Gynecologic Emergency: 13/130713.

\section{Consent for publication}

Not applicable

\section{Competing interests}

The authors have no competing interests to report

\section{Funding}

This research did not receive any specific grant from funding agencies in the public, commercial, or notfor-profit sectors

\section{Authors contributions}

Nikolaos Vrachnis: Designed the study and the ALSG course, wrote and critically revised the manuscript Nikolaos Antonakopoulos: participated in the ALSG courses, retrieved data and wrote the manuscript Antigoni Tsigirlioti: participated in the ALSG courses, retrieved data and wrote the manuscript Vasilios Pergialiotis: performed the statistical analysis and wrote the manuscript

Nicoleta lacovidou: retrieved data and wrote the manuscript

Zoi lliodromiti: wrote and ciritically revised the manuscript

All authors have read and approved the manuscript

Availability of data and materials: The datasets used and/or analysed during the current study available from the corresponding author on reasonable request.

Acknowledgements: The ALSG program instructors who trained the participants in the courses 


\section{References}

1. Buck-Barrett I, Squire I. The use of basic life support skills by hospital staff; what skills should be taught? Resuscitation 2004, 60(1):39-44.

2. Kashiura M, Hamabe Y, Akashi A, Sakurai A, Tahara Y, Yonemoto N, Nagao K, Yaguchi A, Morimura N. Association between cardiopulmonary resuscitation duration and one-month neurological outcomes for out-of-hospital cardiac arrest: a prospective cohort study. BMC anesthesiology. 2017;17(1):59.

3. Matsuyama T, Kitamura T, Kiyohara K, Nishiyama C, Nishiuchi T, Hayashi Y, Kawamura T, Ohta B, Iwami T. Impact of cardiopulmonary resuscitation duration on neurologically favourable outcome after out-of-hospital cardiac arrest: A population-based study in Japan. Resuscitation. 2017;113:1-7.

4. Hirlekar G, Karlsson T, Aune S, Ravn-Fischer A, Albertsson P, Herlitz J, Libungan B. Survival and neurological outcome in the elderly after in-hospital cardiac arrest. Resuscitation. 2017;118:101-6.

5. Shaghashi A, Hassanzadeh S. The effect of formal training of cardiopulmonary resuscitation skills on medical students perceived self sufficiency. J Med Educ. 2004;5(1):25-8.

6. Passali C, Pantazopoulos I, Dontas I, Patsaki A, Barouxis D, Troupis G, Xanthos T. Evaluation of nurses' and doctors' knowledge of basic \& advanced life support resuscitation guidelines. Nurse Educ Pract. 2011;11(6):365-9.

7. Kallestedt ML, Berglund A, Herlitz J, Leppert J, Enlund M. The impact of CPR and AED training on healthcare professionals' self-perceived attitudes to performing resuscitation. Scand J Trauma Resusc Emerg Med. 2012;20:26.

8. Semeraro F, Scapigliati A, Tammaro G, Olcese U, Cerchiari EL, Ristagno G. Advanced life support provider course in Italy: A 5-year nationwide study to identify the determinants of course success. Resuscitation. 2015;96:246-51.

9. Hopstock LA. Cardiopulmonary resuscitation; use, training and self-confidence in skills. A self-report study among hospital personnel. Scand J Trauma Resusc Emerg Med. 2008;16:18.

10. Kaye W, Mancini ME, Rallis SF. Advanced cardiac life support refresher course using standardized objective-based Mega Code testing. Critical care medicine. 1987;15(1):55-60.

11. Yang CW, Yen ZS, McGowan JE, Chen HC, Chiang WC, Mancini ME, Soar J, Lai MS, Ma MH. A systematic review of retention of adult advanced life support knowledge and skills in healthcare providers. Resuscitation. 2012;83(9):1055-60.

12. Au K, Lam D, Garg N, Chau A, Dzwonek A, Walker B, Tremblay L, Boet S, Bould MD. Improving skills retention after advanced structured resuscitation training: A systematic review of randomized controlled trials. Resuscitation. 2019;138:284-96.

13. Palese A, Trenti G, Sbrojavacca R. [Effectiveness of retraining after basic cardiopulmonary resuscitation courses: a literature review]. Assist Inferm Ric. 2003;22(2):68-75.

14. Cline DM, Welch KJ, Cline LS, Brown CK. Physician compliance with advanced cardiac life support guidelines. Ann Emerg Med. 1995;25(1):52-7. 
15. Moser DK, Coleman S. Recommendations for improving cardiopulmonary resuscitation skills retention. Heart lung: the journal of critical care. 1992;21(4):372-80.

\section{Figures}

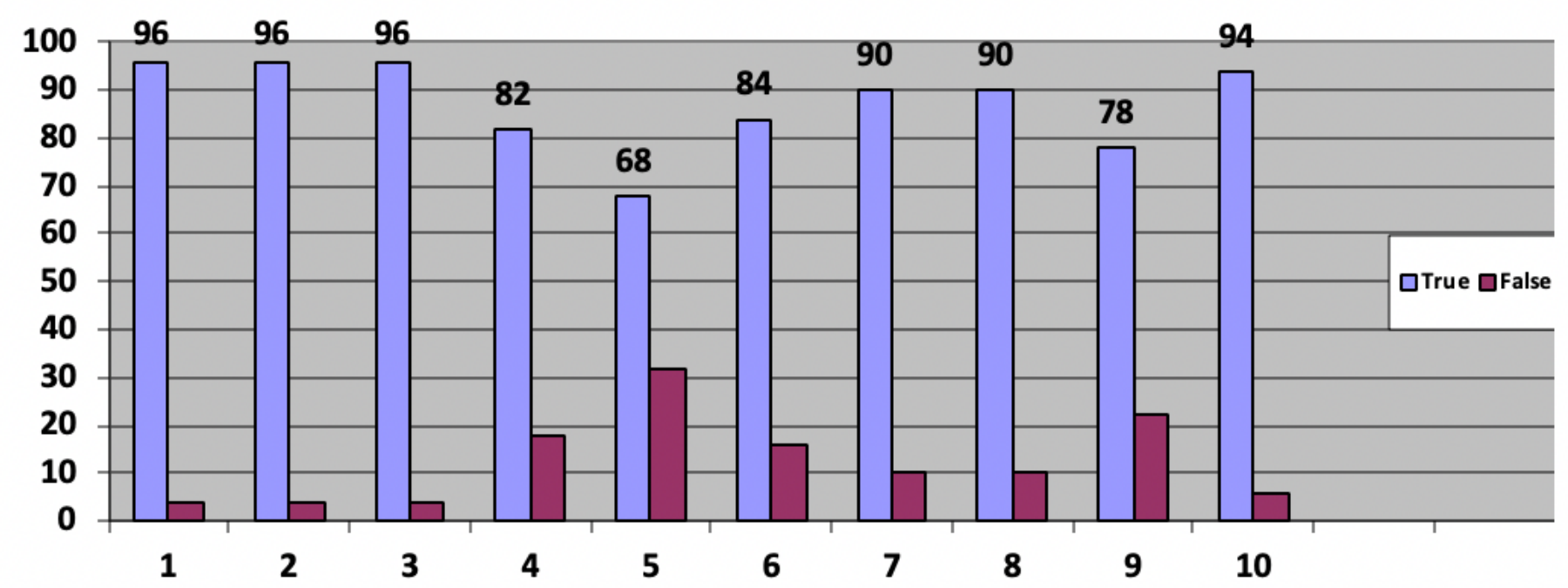

\section{Figure 1}

Questionnaire scores per question Question 1: first action to unconsciousness Question 2: breathing assessment Question 3: first step in resuscitation Question 4: chest compressions technique Question 5: chest compressions rate Question 6: compressions to ventilations ratio Question 7: defibrillation technique Question 8: defibrillation effectiveness Question 9: CPR evaluation intervals Question 10: CPR complications

\section{Supplementary Files}

This is a list of supplementary files associated with this preprint. Click to download.

- Questionnaire.docx 